\title{
Reduced density due to logging and its consequences on mating system and pollen flow in the African mahogany Entandrophragma cylindricum
}

\author{
M Lourmas ${ }^{1,2}$, F Kjellberg ${ }^{2}$, H Dessard ${ }^{1}$, HI Joly ${ }^{1,2}$ and M-H Chevallier, ${ }^{1,2}$ \\ ${ }^{1}$ Cirad-Forêts, Campus International de Baillarguet, Montpellier, France and ${ }^{2}$ CEFE, UMR 5175 CNRS, Montpellier, France
}

\begin{abstract}
In tropical forests, selective logging removes large trees that are often the main contributors to pollination. We studied pollination patterns of the African mahogany, Entandrophragma cylindricum (Sapelli). We investigated two plots in Cameroon corresponding to three tree densities: unlogged forest (Ndama 2002), a mildly logged forest 1 year after logging (Ndama 2003) and a severely logged forest 30 years after logging (Dimako). We used four microsatellite markers to perform paternity analysis. Selfing remained below $2 \%$ in all treatments. Pollen flow was mainly long distance but with some proximity effects. Average observed within-plot pollination distances were 338,266 and $385 \mathrm{~m}$, and pollination by trees outside the plots was $70 \%$ (Ndama 2002), 74\% (Ndama
\end{abstract}

2003) and 66\% (Dimako). Despite sampling a limited number of seeds from a limited number of mother trees, we obtained seeds sired by $35.6-38.3 \%$ of the potential within-plot pollen donors. While trees $20 \mathrm{~cm}$ in diameter contributed to pollination, results in Dimako suggest that individual larger trees contribute more to pollination than small ones. This effect was not detected in the other treatments. The results suggest extensive pollen flow in Sapelli. Hence, in Sapelli, the main limiting factor for regeneration after logging may be a reduction in the number of trees capable of producing seeds rather genetic effects due to limits to pollen dispersal.

Heredity (2007) 99, 151-160; doi:10.1038/sj.hdy.6800976; published online 2 May 2007

Keywords: tropical forest; mating system; selective logging; microsatellites; paternity analysis; pollen dispersal

\section{Introduction}

Predicting the fate of genetic diversity of a timber tree species depends on our understanding of the consequences of logging on its reproductive biology. Selective logging of large trees is a common form of harvesting in tropical forests; only trees large enough to reach a minimum diameter cutting limit (MDCL) are cut. In selective logging, forest cover is globally maintained and timber is extracted along roads opened during harvesting operations and then abandoned. However, the large trees harvested are also likely to have been the main contributors to reproduction, both as seed producers and as pollen dispersers. Therefore, reducing reproductive tree density through selective logging may have drastic effects on gene flow, and may increase selfing and correlated matings.

Correspondence: Dr M-H Chevallier, CEFE, UMR 5175 CNRS, 1919 route de Mende, F-34293 Montpellier Cedex 5, France.

E-mail:marie-helene.chevallier@cefe.cnrs.fr

This paper is dedicated to late Caroline Dubois who started the field observations on the sites.

This paper is part of the PhD of Mathieu Lourmas at the University of Montpellier, France, on the impact of human activities on population genetics and conservation biology of Entandrophragma cylindricum in the Congo Basin. The authors are participating in several projects that aim at understanding genetic population processes in tropical trees and apply these results to their conservation.

Received 9 September 2005; revised 17 October 2006; accepted 16 February 2007; published online 2 May 2007
Most emergent canopy tree species of tropical forests are hermaphroditic, occur at low density (less than one mature tree per hectare) and are animal pollinated (Bawa, 1990). They exhibit high outcrossing rates associated with close to complete self-incompatibility (Loveless, 1992; Doligez and Joly, 1997; Nason and Hamrick, 1997). Nevertheless, in pristine or 'little disturbed' habitats pollination often occurs preferentially between neighboring conspecifics resulting in correlated matings (Murawski and Hamrick, 1991; Stacy et al., 1996; Dawson et al., 1997; Kaufman et al., 1998; Nagamitsu et al., 2001; Dutech et al., 2002) though often in association with substantial long-distance pollen dispersal (Hamrick and Murawski, 1990; White et al., 2002; Latouche-Hallé et al., 2004).

Two types of responses to density variation have been observed in tropical forest trees. In some species, lower densities not only result in selfing, higher inbreeding and genetic relatedness within progenies (e.g., Murawski and Hamrick, 1991, for nine species under natural conditions; Lee et al., 2000; Obayashi et al., 2002), but also lowered fecundity (Ghazoul et al., 1998; Cunningham, 2000). Other species seem to be largely unaffected by low population densities (e.g., Kitamura et al., 1994; Hall et al., 1996). Such variation might be best explained by the behavior of the main pollinators and the type of incompatibility system. Species pollinated by low-mobility insects such as thrips and/or small beetles could then be opposed to species pollinated by long-distance pollinators such as Apis and Trigona bees (Obayashi et al., 
2002). Whatever the pollinators, there is probably always a critical density of flowering trees in a forest below which pollination patterns are severely affected.

In view of this uncertainty about the response to natural or man-induced variation in density, predictions about the consequences of selective logging on the reproductive biology of tropical trees are hazardous.

If timber harvesting reduces the number of pollinators per seed-bearing tree or increases selfing by delaying fertilization by allo-pollen, then the genetic consequences should be easy to monitor. Genetic relatedness within progenies is expected to increase as a consequence of increased selfing and/or decreased number of pollen donors. Therefore, levels of allelic and genetic diversity are predicted to show a stronger reduction between fruiting trees and their progenies after logging than before. Analyses of paternity should also provide strong insights into the processes involved.

We explored the effect of density reduction due to logging on the reproductive biology of a tropical timber species, the African mahogany, Entandrophragma cylindricum Sprague (Meliaceae), commonly known by its trade name 'Sapelli'. We asked the following questions. (1) Does mating occur preferentially between neighboring trees in Sapelli? (2) Does moderate logging limit the number of potential fathers favored by proximity in such a way that seeds from a tree have reduced numbers of fathers? (3) Does severe logging reduce the number trees that are close enough to get a proximity advantage and hence increase the diversity of male parents of the seed crop on a tree? (4) Does low tree density result in increased selfing?

To answer these questions, we studied Sapelli in two plots in Cameroon, corresponding to three situations (which we henceforth term treatments): one plot before logging; the same plot 1 year after logging - to explore the impact of a limited reduction of density due to selective logging; and a low density plot logged several decades ago - to explore the long-term impact of low density. Within each plot and situation, we estimated the contribution of each mature tree to the fertilization of the seeds produced by focal trees by conducting an analysis of paternity. We also assessed whether mating in Sapelli occurs preferentially between neighboring trees, and whether large diameter trees are the main contributors to pollination.

\section{Materials and methods}

\section{Species and sample collection}

Species of the mahogany family are important components of tropical forests throughout the world, both because of their structural role within the forest (they are often dominant trees) and because of the commercial value those species used for timber. Sapelli is a longlived timber tree species of high commercial value found from Sierra Leone east to the Democratic Republic of Congo and to Uganda, in tropical evergreen and semideciduous forests (Hall and Swaine, 1976). In the continuous tropical forest cover of the Congo Basin, trees are widely spaced and density is typically lower than five flowering individuals per hectare. In Cameroon, it is legal to selectively harvest Sapelli trees with a diameter at breast height $(\mathrm{DBH}) \geqslant 100 \mathrm{~cm}$.
Sapelli was considered to be hermaphroditic by Aubreville (1959). More recent studies suggest that it is monoecious (separate male and female flowers on the same tree) (Styles, 1972). Meliaceae are insect pollinated, mainly by bees and moths (Styles and Khosla, 1976). Most species produce a sickly sweet perfume, permitting their detection from a considerable distance (Styles, 1972). Sapelli has a broad, diffuse distribution.

Sapelli trees may begin to flower when reaching $20 \mathrm{~cm}$ in DBH (C Dubois, unpublished data), but only set seed when reaching about $50 \mathrm{~cm}$ DBH (Durrieu de Madron and Daumerie, 2004). On an average year, about onethird of mature trees produce fruits, but flowering and fruiting are irregular among individuals and years $(C$ Dubois, unpublished data) and seed production is erratic (Hawthorne, 1995). Thus, for analysis of paternity, we considered that all trees with a diameter $\geqslant 10 \mathrm{~cm} \mathrm{DBH}$ were potential pollen donors, as a conservative measure to ensure that all the trees that flowered within the plot had been genotyped.

We re-censused two plots in Cameroon, and mapped, sampled and genotyped with microsatellites the entire population of trees with $\mathrm{DBH} \geqslant 10 \mathrm{~cm}$. The first site, named Ndama (latitude $3^{\circ} 34^{\prime} \mathrm{N}$, longitude $14^{\circ} 24^{\prime} \mathrm{E}$ ) (a square 100 ha plot), was an old-growth forest until selective logging in 2002. The second site, named Dimako (latitude $4^{\circ} 20^{\prime} \mathrm{N}$, longitude $13^{\circ} 39^{\prime} \mathrm{E}$ ) (a rectangular 440 ha plot) was $150 \mathrm{~km}$ distant and was severely logged once, 30 years ago, and densities of large trees are still low. Indeed Sapelli grows slowly. Détienne et al. (1998) provide an estimate of yearly growth of $4.7 \mathrm{~mm}$ in diameter. Hence the trees at Dimako are expected to have grown by only $14 \mathrm{~cm}$ in $\mathrm{DBH}$ since logging. The whole area around Dimako had been logged so we could monitor the effect of large-scale density reduction. Both plots were part of the same continuous forest without any major physical barrier. Densities of small Sapelli trees $(10 \mathrm{~cm} \leqslant \mathrm{DBH}<50 \mathrm{~cm})$ were almost identical in the three treatments, suggesting similar original global densities. Densities of Sapelli trees $(\mathrm{DBH} \geqslant 10 \mathrm{~cm})$ per hectare in the three treatments were as follows: 1.52 in Ndama before logging (termed 'Ndama 2002'), 1.13 in Ndama after logging ('Ndama 2003') and 0.28 in Dimako. The average diameters of potential pollen donors were 93, 82 and $54 \mathrm{~cm} \mathrm{DBH}$, respectively. Logging intensity was observed to be about $50 \%$ of legal-sized trees in Ndama 2002, and was probably much higher in Dimako as both densities and tree diameters were still very low.

We examined three subsets of individuals: (1) the whole population of mature trees, termed 'potential within-plot pollen donors', from which we extracted (2) a sample of fruiting trees, termed 'mother trees' and (3) the progenies of these 'mother trees'. We sampled seeds under a series of fruiting trees at the end of the fruiting period in Ndama (in 2002 and in 2003), and in Dimako (in 2003). We selected a subset of focal mother trees. These focal trees all had a $\mathrm{DBH} \geqslant 50 \mathrm{~cm}$. They were chosen to be distributed haphazardly within the plot. Indeed, our goal was to obtain dispersed distribution of mothers within the plot so as to sample the pollen clouds in different areas. An alternative would have been to choose individuals located at the center of the plots, so as to increase the likelihood of identifying the father of seeds, but by sampling closely spaced trees, we would have reduced the independence of the estimates from 
different mothers. Precision would have been at the expense of generality. Similarly, we tried to genotype equal numbers of seeds under each female parent. Thus, we could analyze the relationship between size of a male tree, its position relative to a focal mother tree and its contribution to the fertilization of seeds, and this independently of female parent crop size. In the following, 'male success' will refer to this estimate, which ignores differences in crop size. We wanted to highlight neighborhood effects rather that crop size variance effects.

Spatial analyses conducted a posteriori (see below for the methodology employed) showed that there were no significant difference in each treatment between the distribution of distances between all pairs of individuals and the distribution of distances between sampled mothers and potential within-plot pollen donors $(P=0.089$ in Ndama 2002, $P=0.52$ in Ndama 2003 and $P=0.78$ in Dimako). Seeds were collected under crowns of mother trees on the forest floor, toward the end of the fruiting period. All sampled mother trees presented unique combinations of alleles so that we could establish that the 'mother tree' was a true parent, either paternal or maternal, of the seed. Such seeds could either be seeds produced by the maternal tree or were seeds from a neighboring tree sired by pollen from the 'maternal tree'. Only very few seeds (less than 5\%) were not the offspring of the putative mother. They were discarded from the analysis. This feature demonstrates that most of the times, the putative mother tree was effectively the mother tree. Otherwise, many more cases of genotype discrepancy would have been detected. We retained for further analysis only the mothers for which $\geqslant 10$ seeds were genotyped without ambiguity. We analyzed the seeds of 16, 20 and 15 mothers in Ndama 2002, Ndama 2003 and Dimako, respectively.

\section{Molecular methods}

DNA of adult trees was extracted from leaves according to Garcia et al. (2004). For the progenies, DNA was extracted from seeds. Extraction followed the method of Garcia et al. (2004) except that the final aliquot was eluted in $300 \mu \mathrm{l}$ of Tris-ethylenediaminetetraacetic acid buffer rather than in $50 \mu \mathrm{l}$ of pure water. Before extraction, the seed coat was removed manually, and seeds were then ground to powder in liquid nitrogen.

We multiplexed in the same polymerase chain reaction (PCR) the four microsatellite markers that maximized the cumulative exclusion probability $(\mathrm{EPC}=99.9 \%$; see section on paternity analysis below), estimated following Gerber et al. (2000). These markers were pEcCIR 244, 271, 156 and 12 (Garcia et al., 2004) ranked in decreasing order of exclusion power. We computed exclusion probabilities with the FaMoz software (Gerber et al., 2003a).

The PCR multiplex solution was adapted from Chaix et al. (2002) to Sapelli. The solution ( $24 \mu \mathrm{l}$ total volume) contained $0.4 \mu \mathrm{l}$ of the four dNTPs $(100 \mu \mathrm{M}), 4.8 \mu \mathrm{l}$ of $10 \times$ reaction buffer $(750 \mathrm{mM}$ Tris- $\mathrm{HCl}, \mathrm{pH} 8.8,200 \mathrm{mM}$ $\left(\mathrm{NH}_{4}\right)_{2} \mathrm{SO}_{4}, 0.1 \%$ Tween 20$), 4.8 \mu \mathrm{l} \mathrm{MgCl}_{2}(25 \mathrm{mM}), 5.5 \mu \mathrm{l}$ of mix of the four primer couples $(10 \mu \mathrm{M}), 4 \mu \mathrm{l}$ of nuclear DNA (20-30 ng), $0.4 \mu \mathrm{l}$ (2 units) of Taq DNA polymerase (Eurogentec Red GoldStar, Serain, Belgium) and $4.1 \mu \mathrm{l}$ of pure water. One primer from each pair was dye labeled; colors of labels were chosen according to marker size range and did not overlap. Cycling conditions were: denaturing initialized at $94^{\circ} \mathrm{C}$ for $4 \mathrm{~min}, 40$ cycles of $30 \mathrm{~s}$ at $94^{\circ} \mathrm{C}, 30 \mathrm{~s}$ at the annealing temperature of $55^{\circ} \mathrm{C}$ and $1 \mathrm{~min}$ at $72^{\circ} \mathrm{C}$, with a final extension step of $10 \mathrm{~min}$ at $72^{\circ} \mathrm{C}$. PCRs were conducted using a PTC100 thermocycler (MJ Research, Bio-Rad, Hercules, CA, USA). A total of $2 \mu \mathrm{l}$ of PCR products were pooled in $15 \mu \mathrm{l}$ of deionized formamide and $0.2 \mu \mathrm{l}$ of GeneScan-500XLROX size standard and analyzed on an ABI Prism 310 Genetic Analyser (Perkin Elmer, Waltham, MA, USA). Size of each fragment was determined using the GeneScan program (Applied Biosystems, Foster City, CA, USA).

\section{Data analysis}

Paternity analysis: We did a paternity analysis considering as potential pollen donors all genotyped trees, including the sampled mothers themselves. Maximum-likelihood estimates were obtained using the FaMoz software (Gerber et al., 2003a). We assigned paternity based on the $\Delta$ statistic, that is, the difference in log of the odds ratio (LOD) scores (logarithm of the likehood ratio) of the two most likely pollen donors, as described by Marshall et al. (1998), provided that the scores of the fathers were higher than the LOD score thresholds given by simulation (see Gerber et al., 2003a for details). Analyses led to three situations: no father identified inside the plot, a single father inside the plot or two or more fathers within the plot among which we were not able to discriminate.

We first estimated the percentage of pollination events originating from outside the plot (GFO, gene flow from outside) for each mother sampled, and averaged those values to obtain an estimate for the entire plot. GFO is given as the percentage of each mother's progeny for which no pollen donor was identified inside the plot. We used Spearman's nonparametric rank correlation test to detect whether GFO decreased with distance of the mother tree from the closest edge of the plot (one-tailed test).

We then discarded the few seeds for which two or more potential fathers were found and used only seeds for which a single father was identified (called a 'known within-plot pollen donor'). In each of the three treatments, this category comprised more than $90 \%$ of the total number of seeds for which at least one potential father was identified within the plot. When a single flowering tree was identified as the father of several seeds from a given mother, we considered this to represent several independent mating events. We computed the percentage of known within-plot pollen donors among the potential within-plot pollen donors, the percentage of self-pollination, the average $\mathrm{DBH}$ of known within-plot pollen donors and the distributions of $\mathrm{DBH}$. We estimated the observed within-plot male mating success $\left(\mathrm{MMS}_{j}\right)$ of each known pollen donor $j$ as follows:

$$
M M S=\sum_{i=1}^{n_{i}} \frac{S E}{S E_{i}} m_{i j}
$$

where $n_{i}$ is the total number of mother trees, $m_{i j}$, the observed number of seeds of mother $i$ fertilized by pollen donor $j, S E$, the mean sampling effort, that is the average number of seeds sampled under mother trees in that treatment; and $S E_{i}$ the sampling effort for mother tree $i$, 
that is the number of seeds sampled from this particular mother. We averaged the $\mathrm{MMS}_{j}$ to obtain the MMS at the plot level. Distribution of MMS values in Ndama 2002 was compared to the distributions in Ndama 2003 and Dimako using Kolmogorov-Smirnov tests.

To detect whether larger trees were more likely to contribute to pollination than smaller trees, we compared, for each treatment, the DBH distributions of effective and potential pollen donors using KolmogorovSmirnov tests. To test whether tree density and size distribution affected which size classes contributed to pollination, the $\mathrm{DBH}$ distribution of known pollen donors observed in Ndama 2002 was compared to those of Ndama 2003 and Dimako. To detect whether, among within-plot successful pollen donors, large trees fertilized more seeds than small trees, we compared the distribution of MMS values among the five $\mathrm{DBH}$ size class: $\mathrm{DBH}<50 \mathrm{~cm}, \mathrm{DBH} \in(50-79) \mathrm{cm}, \mathrm{DBH} \in(80-99) \mathrm{cm}$, $\mathrm{DBH} \in(100-119) \mathrm{cm}, \mathrm{DBH} \geqslant 120 \mathrm{~cm}$ using a KruskalWallis test. When significant, we established which differences among size classes contributed most to this significance by calculating pair-wise Mann-Whitney tests. Similarly, we compared MMS values among treatment for each DBH class using a Kruskal-Wallis test and when significant we applied Mann-Whitney tests.

Spatial analysis: We tested for directionality of pollen flow using Kolmogorov-Smirnov tests. For each mother tree, we determined the angle (relative to north) from each effective and each potential within-plot pollen donor to that tree. We then divided angles into classes (15 degarc) and compared distributions of angles between known within-plot pollen donors and mother trees, and between potential within-plot pollen donors and mother trees.

Interindividual distances between mother trees and known within-plot pollen donors were considered as 'observed within-plot pollination distances'. We use this terminology in the following although what is really measured is functional observed within-plot fertilization distance as incompatibilities and nonrandom abortion of young seeds could occur. We computed the mean distance between mother tree and potential within-plot pollen donor, and mean observed within-plot pollination distance in each treatment. As the size of the plot at Dimako is 4 times larger than at Ndama, we also computed the average observed within-plot pollination distance in Dimako discarding pollen dispersal events further than $1397 \mathrm{~m}$, which is the maximal distance observed between two trees in Ndama. We compared the distribution of interindividual distances between mother trees and known within-plot pollen donors (for each focal female tree, each pollen donor was only counted once even if it had sired several seeds) with the distribution of interindividual distances between mother trees and potential pollen donors, and with the distribution of all interindividual pair-wise distances within each treatment. We did a multiple comparison test ( $t$-pair-wise test) for which $P$-values were adjusted to conserve a global 5\% significance level using the $f d r$ method of Benjamini and Hochberg (1995). We used KolmogorovSmirnov tests to compare the distribution of pollination distances between Ndama 2002 and Ndama 2003, and between Ndama 2002 and Dimako. As the plot in
Dimako was four times larger than the one at Ndama, we repeated the procedure without taking into account pollination distances above $1397 \mathrm{~m}$.

Outcrossing rate: The multilocus population outcrossing rate $\left(t_{\mathrm{m}}\right)$, the average single-locus population outcrossing rates $\left(t_{\mathrm{s}}\right)$ and biparental inbreeding rates $\left(t_{\mathrm{m}}-t_{\mathrm{s}}\right)$ (Ritland, 2002) were estimated from seed and mother tree genotypes using MLTR, version 3.0 (Ritland, 2002). We performed 500 bootstraps to estimate standard deviations of $t_{\mathrm{m}}, t_{\mathrm{s}}$ and $\left(t_{\mathrm{m}}-t_{\mathrm{s}}\right)$. The genetic relatedness between progenies was estimated using the multilocus kinship coefficient developed by Loiselle et al. (1995) computed with the software SPAGeDi 1.0 (Hardy and Vekemans, 2002). Kinship values were computed in each treatment for each progeny family using as allelic frequencies of the reference population those issued from the whole progeny sample. Kinship values were averaged in each treatment among progeny families to obtain a mean estimate at the plot level. We used Kolmogorov-Smirnov tests to compare the distributions of the kinship values among progeny families between Ndama 2002 and Ndama 2003, and between Ndama 2002 and Dimako.

Diversity statistics: We computed the average number of alleles per locus. We measured the allelic richness standardized per locus in potential within-plot pollen donors and in progenies in each treatment according to El-Mousadik and Petit (1996) using Fstat (Goudet, 1995). We computed observed and expected heterozygosity levels (Nei's index of genetic diversity) and F-statistics using Genepop 3.3 (Raymond and Rousset, 1995), and tested significance of heterozygote deficits following Weir and Cockerham (1984, in Raymond and Rousset, 1995). We tested differences between $H_{\mathrm{e}}$ and $F_{\text {is }}$ values among the different subsets using Fstat.

\section{Results}

Paternity analysis: male contributions to pollination

Most progenies were sired by males located outside the plot $(\mathrm{GFO}=70,74$ and 66\% in Ndama 2002, Ndama 2003 and Dimako, respectively) (Table 1). The proportion of GFO decreased or tended to decrease with the distance from the edge of the plot (one-tailed Spearman's rank correlation tests, Ndama $2002 P<0.01$, Ndama 2003 $P<0.07$, Dimako $P<0.05$; Figure $1 \mathrm{a}, \mathrm{b}, \mathrm{c}$, respectively). Depending on the mother, GFO varied from 40 to $94 \%$ in Ndama 2002, 33-100\% in Ndama 2003 and 43-92\% in Dimako.

The estimated percentage of self-pollination was lower than $2 \%$ in all three treatments (Table 1) and did not differ significantly among treatments.

In Ndama 2003 and Dimako some trees $(20 \mathrm{~cm}$ in $\mathrm{DBH})$ were recorded as effective pollen donors. Of the potential within-plot pollen donors, 35.6, 38.3 and $36.4 \%$ were identified as known pollen donors in Ndama 2002, Ndama 2003 and Dimako, respectively.

Average numbers of seeds sired by individual withinplot known pollen donors were 1.47, 2.33 and 2.66 in Ndama 2002, Ndama 2003 and Dimako, respectively. Individual MMS values tended to increase with decreasing density values from Ndama 2002 to Ndama 2003 and 
Table 1 Paternity assignment and mating system

\begin{tabular}{lcccrr}
\hline & GFO (\%) & Selfing $(\%)$ & $\mathrm{t}_{m}$ (s.d.) & $\mathrm{t}_{s}$ (s.d.) & $\mathrm{t}_{m}-\mathrm{t}_{s}($ s.d.) \\
\hline Ndama 2002 & 70.3 & 1.49 & $0.981(0.017)$ & $0.959(0.014)$ & $0.021(0.016)$ \\
Ndama 2003 & 73.9 & 1.60 & $0.983(0.009)$ & $0.959(0.013)$ & $0.025(0.010)$ \\
Dimako & 65.9 & 1.20 & $0.980(0.008)$ & $0.956(0.012)$ & $0.024(0.009)$
\end{tabular}

Abbreviations: GFO, gene flow from outside, percentage of seeds for which no pollen donors were found inside the plot; $t_{\mathrm{m}}$, estimated multilocus outcrossing rate; $t_{\mathrm{m}}-t_{\mathrm{s}}$, biparental inbreeding; $t_{\mathrm{s}}$, estimated average single locus outcrossing rate; selfing, percentage of selfpollination according to paternity analysis.
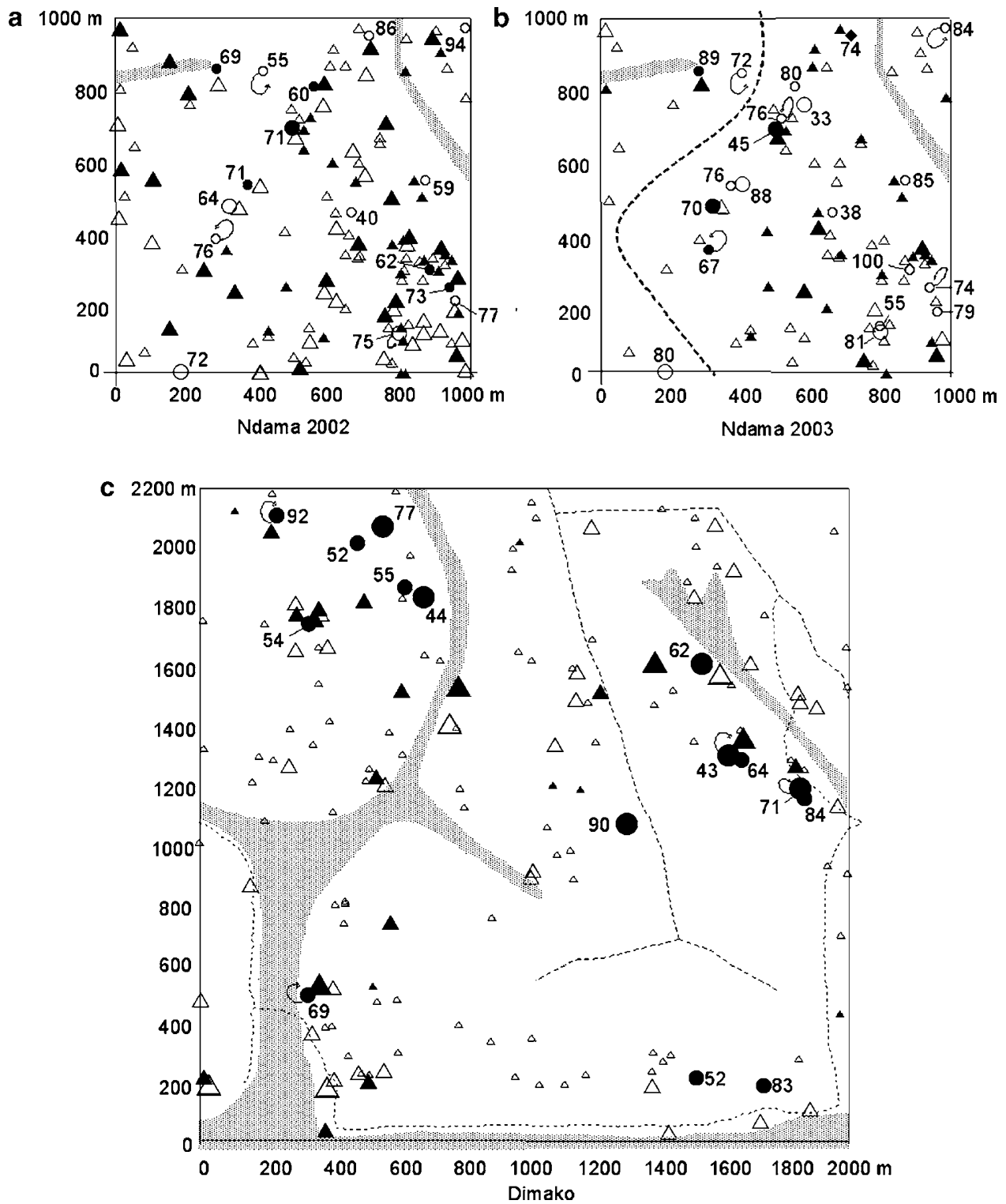

Figure 1 Maps of the three treatments. (a) Ndama 2002, (b) Ndama 2003 and (c) Dimako. Coordinates are in meters. Symbols show tree location (triangles = potential pollen donors, circles = sampled mothers), dashed lines are exploitation roads, dotted areas are rivers or marshes. Large symbols, tree $\mathrm{DBH} \geqslant 100 \mathrm{~cm}$, medium symbols, $\mathrm{DBH} \in(50-99) \mathrm{cm}$, small symbols, $\mathrm{DBH}<50 \mathrm{~cm}$ (this last class of trees were only plotted on the Dimako map); empty triangles, potential pollen donors not identified as effective ones; filled triangles or filled circles (for mothers), identified effective pollen donor (known pollen donor); empty circles, mothers not identified as pollen donors; arrows, selfpollination events. Individual GFO rate is given for each mother close to its location.

to Dimako, but were only significantly different between Ndama 2002 and Dimako $(P<0.001)$.

The average $\mathrm{DBH}$ of potential within-plot pollen donors were $93 \mathrm{~cm}$ (Ndama 2002), $82 \mathrm{~cm}$ (Ndama 2003) and $54 \mathrm{~cm}$ (Dimako), and those of known within-plot pollen donors were 102,83 , and $88 \mathrm{~cm}$, respectively. Distributions of DBH of known pollen donors did not differ from those of potential pollen donors in Ndama 
2002 and 2003 ( $P=0.41$ and $P=0.97$, respectively) Figure $2 a$ and $b$ ), while they were significantly different in Dimako, with a relatively stronger contribution of large trees of the DBH (100-119) class $\left(P=5.4 \times 10^{-5}\right)$ (Figure 2c). This result may also be partly attributed to the abundance of individuals in the $\mathrm{DBH}<50$ size class in Dimako which contributed very little to reproduction on all plots. The distribution of the DBH of known pollen donors was significantly different between Ndama 2002 and Ndama $2003\left(P=1 \times 10^{-3}\right)$, and between Ndama 2002 and Dimako $\left(P=8 \times 10^{-4}\right)$. With decreasing densities and a size distribution shifting toward smaller trees, the global contribution of smaller trees to pollination increased.

a

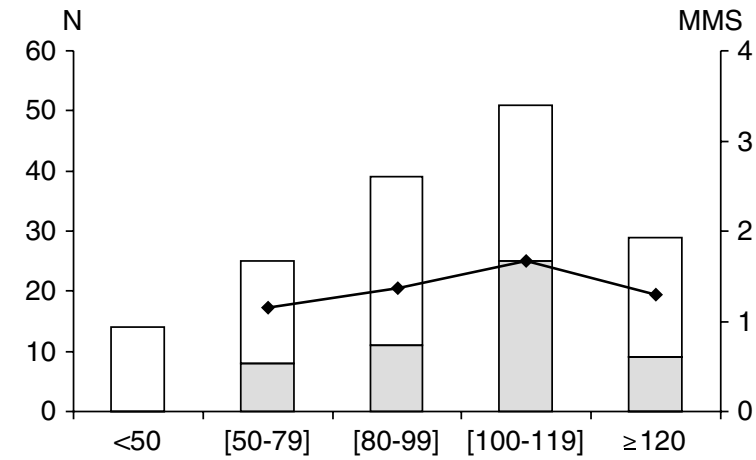

b

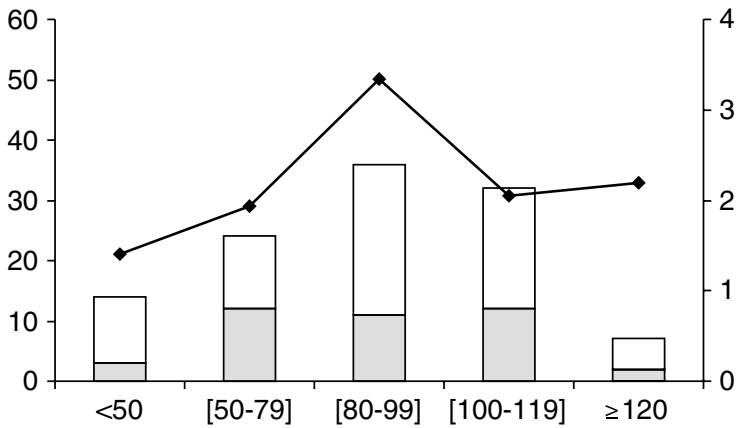

c

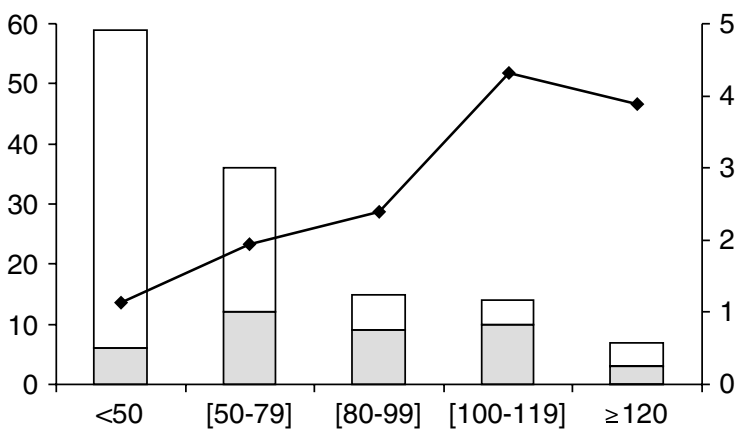

Figure 2 MMS and DBH distributions of potential and known pollen donors. (a) Ndama 2002, (b) Ndama 2003 and (c) Dimako. Abscissa, DBH classes in centimeter. Left ordinnate axis (histograms), DBH distributions of potential pollen donors (white bar) plotted with the DBH distributions of known pollen donors (gray bar), given in number of trees. Right ordinnate axis (curve), median values of the MMS of effective pollen donors (MMS) per diameter class (see text for computing details). Note that the density of small trees $(\mathrm{DBH}<50 \mathrm{~cm})$ is equivalent in the three treatments, but the numbers are different because the Dimako plot is 4.4 times larger than the Ndama plot.
The Kruskal-Wallis tests within treatment showed that MMS values per size class differed only within the Dimako treatment; MMS values in DBH size class (100$119)$ were higher than in all smaller size classes (class $<50, P=0.002$; class (50-79), $P=0.014$, class (80-99), $P=0.036)$ and MMS values in size class (50-79) were higher than in $\mathrm{DBH}$ size class $<50 \mathrm{~cm}(P=0.025)$.

MMS within size class were heterogeneous among treatments for size classes (100-119) and $>120 \mathrm{~cm}$ (Kruskal-Wallis respectively $P=0.002$ and $P=0.046$ ). MMS were higher in Dimako than in Ndama 2002 for DBH size classes (100-119) $(P=0.006)$, and $\geqslant 120 \mathrm{~cm}$ $(P=0.036)$ and higher in Dimako than in Ndama 2003 for DBH size class $(100-119)(P=0.006)$.

Paternity analysis: patterns of pollen dispersal

We detected no significant directionality in pollen flow in any of the three treatments $(P=0.091, P=0.477$ and $P=0.743$, in Ndama 2002, Ndama 2003 and Dimako, respectively).

Average observed within-plot pollination distances, for the trees analyzed, were $338 \mathrm{~m}$ (Ndama 2002), $266 \mathrm{~m}$ (Ndama 2003) and $385 \mathrm{~m}$ (Dimako) (Figure 3c-, 3f-, 3i-, respectively). The average observed within-plot pollination distance was reduced to $311 \mathrm{~m}$ at Dimako when discarding pollination events above $1397 \mathrm{~m}$, the maximum distance between individuals at Ndama. Longdistance within-plot pollen flow was detected in the three treatments. In Ndama, the highest observed withinplot pollination distance was $1027 \mathrm{~m}$ in 2002 and $944 \mathrm{~m}$ in 2003. In Dimako, the largest plot, we evidenced mating events at distances up to $2095 \mathrm{~m}$.

The distributions of observed within-plot pollination distances were significantly different from the distribution of pair-wise distances between sampled mothers and potential within-plot pollen donors $\left(P=5.2 \times 10^{-5}\right.$ in Ndama 2002, $P=5.9 \times 10^{-10}$ in Ndama 2003 and $\mathrm{P}<2 \times 10^{-16}$ in Dimako) (Figure 3b-, c-, e-, f-, h- and i-, respectively). The distributions of observed within-plot

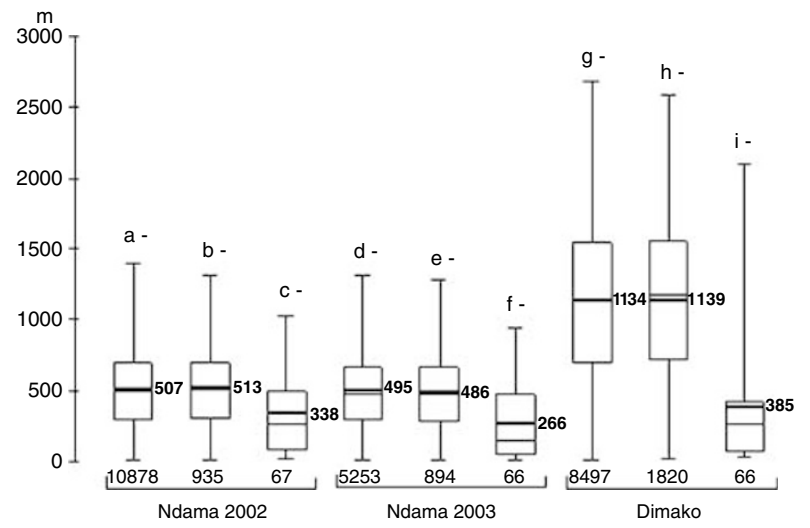

Figure 3 Distributions of distances between all individuals and between sampled mothers and potential and known pollen donors (pollination distances) $\geqslant$, b-, c- Ndama 2002, d-, e-, f- Ndama 2003, g-, h-, i- Dimako. Distributions of pair-wise distances between all individuals (a-, d-, g-), distributions of pair-wise distances between sampled mothers and potential pollen donors (b-, e-, h-) and distributions of pair-wise distances between sampled mothers and known pollen donors, for example pollination distances (c-, f-, i-). Minimum, first quartile, median, mean (bold), third quartile and maximum are given. Class size (under each boxplot) and values of the means (in bold) are reported. 
Table 2 Diversity statistics for potential and known within-plot pollen donors, mothers and progenies

\begin{tabular}{|c|c|c|c|c|c|c|c|c|}
\hline Population & Subset & $\mathrm{N}$ & $\mathrm{N}_{a}$ & A & $\mathrm{H}_{e}$ & $\mathrm{H}_{o}$ & $\mathrm{~F}_{\text {is }}$ & \\
\hline \multirow[t]{4}{*}{ Ndama 2002} & Potential pollen donors & $152(1.52)$ & 25.5 & 14.1 & 0.928 & 0.911 & 0.018 & NS \\
\hline & Known pollen donors & 47 & 20.3 & 11.8 & 0.923 & 0.918 & 0.005 & NS \\
\hline & Mother trees & 16 & 14.8 & 10.2 & 0.927 & 0.969 & -0.046 & NS \\
\hline & Progenies & 269 & 26.5 & 12.6 & 0.917 & 0.878 & 0.043 & * \\
\hline \multirow[t]{4}{*}{ Ndama 2003} & Potential pollen donors & $113(1.13)$ & 24.5 & 13.6 & 0.927 & 0.919 & 0.009 & NS \\
\hline & Known pollen donors & 37 & 19.3 & 12.7 & 0.932 & 0.944 & -0.014 & NS \\
\hline & Mother trees & 20 & 16.0 & 11.2 & 0.930 & 0.988 & -0.062 & * \\
\hline & Progenies & 358 & 26.0 & 12.2 & 0.916 & 0.899 & 0.018 & * \\
\hline \multirow[t]{4}{*}{ Dimako } & Potential pollen donors & $123(0.28)$ & 28.0 & 12.9 & 0.923 & 0.886 & 0.040 & $* * *$ \\
\hline & Known pollen donors & 40 & 19.3 & 10.7 & 0.916 & 0.910 & 0.005 & NS \\
\hline & Mother trees & 15 & 13.8 & 9.1 & 0.912 & 0.967 & -0.060 & NS \\
\hline & Progenies & 334 & 25.8 & 11.8 & 0.911 & 0.873 & 0.043 & $* * *$ \\
\hline
\end{tabular}

Abbreviations: $A$, allelic richness standardized; $N$, sample size $\left(D\right.$, density, given in trees ha $\left.{ }^{-1}\right) ; N_{\mathrm{a}}$, average number of alleles; $H_{\mathrm{e}}$ and $H_{\mathrm{o}}$, expected and observed heterozygosity; $F_{\mathrm{is}}$, deficit in heterozygotes (NS $=P>0.05,{ }^{*} P<0.05,{ }^{* * *} P<0.001$ ).

pollination distances were characterized by an overrepresentation of short distances compared to the distribution of distances between mother and potential pollen donors. The medians of observed within-plot pollination distance distributions were 260, 156 and $268 \mathrm{~m}$ in Ndama 2002, Ndama 2003 and Dimako, respectively, whereas they were 493,481 and $1137 \mathrm{~m}$ for the distribution of distances between mother and potential within-plot pollen donors. For seeds produced by within-plot fertilization, about $50 \%$ resulted from fertilizations by trees located within a radius of 260, 156 and $268 \mathrm{~m}$, from the maternal tree and $25 \%$ from within a radius of 82,53 and $68 \mathrm{~m}$, in Ndama 2002, Ndama 2003 and Dimako, respectively (Figure 3c-, f-, i-). The distributions of observed within-plot pollination distances differed significantly between Ndama 2002 and Ndama $2003(P=0.037)$ but not between Ndama 2002 and Dimako.

\section{Analysis of the mating system}

The multilocus estimates of outcrossing rates $\left(t_{\mathrm{m}}\right)$ were 0.98 in the three treatments, while single-locus estimates of outcrossing rate $\left(t_{\mathrm{s}}\right)$ were 0.96 and were significantly different from the multilocus estimates (Table 1). Consequently, estimates of biparental inbreeding (difference $\left.t_{\mathrm{m}}-t_{\mathrm{s}}\right)$ were low in the three treatments $\left(t_{\mathrm{m}}-t_{\mathrm{s}} \leqslant 0.025\right)$ but consistent and significant. Distributions of kinship coefficient values among progeny families were not significantly different between Ndama 2002 and Ndama 2003, and between Ndama 2002 and Dimako.

\section{Allelic richness and gene diversity}

Genetic diversity parameters for the three treatments are reported in Table 2 . We only found a slight but significant difference between values of the standardized allelic richness $(A)$ between within-plot potential pollen donors and progenies in Dimako $(P<0.05)$, but not between known within-plot pollen donors and progenies in any of the three treatments. The estimates of gene diversity among the different subsets were not significantly different within each treatment. $H_{\mathrm{e}}$ was high in the three treatments and in all the subsets $\left(H_{\mathrm{e}}>0.9\right)$ while the lowest values of $H_{\mathrm{e}}$ were found in the progeny subsets in each treatment $\left(H_{\mathrm{e}}=0.917,0.916\right.$ and 0.911, in Ndama 2002, Ndama 2003 and Dimako, respectively). Significant but low deficits in heterozygotes were found in all progeny subsets (Ndama 2002, $F_{\text {is }}=0.043, P=0.012$; Ndama 2003, $F_{\text {is }}=0.018, P=0.022$; Dimako, $F_{\text {is }}=0.043$, $\left.P<10^{-3}\right)$, and in the potential pollen donors subset of Dimako $\left(F_{\text {is }}=0.020, P<0.0001\right)$. The mother trees in Ndama 2003 presented an excess of heterozygosity $\left(F_{\text {is }}=-0.062, P=0.015\right)$.

\section{Discussion}

\section{Reproductive biology}

As recorded in the literature, seed production appears to start only when trees have reached $50 \mathrm{~cm}$ in $\mathrm{DBH}$ (Durrieu de Madron and Daumerie, 2004); we did not find seeds under smaller trees. However, paternity analysis demonstrated that trees $20 \mathrm{~cm}$ in DBH did contribute to pollination.

In each of the three treatments, mean multilocus estimates of outcrossing rate and paternity analysis gave the same result: independently of flowering tree density, less than $2 \%$ of the seeds were produced by selfing. High outcrossing rate is a common feature of tropical forest trees (for example, Bawa, 1992, Ward et al., 2005). The observation that Sapelli retains high outcrossing rates, even when density is strongly reduced, suggests the existence of a strong self-incompatibility system. Lack of density effects on outcrossing rates is not universal in tropical trees. It has been observed in a number of species (Kitamura et al., 1994; Hall et al., 1996), while, in other cases, reduced densities result in higher selfing rates (Doligez and Joly, 1997; Dayanandan et al., 1999; Lee et al., 2000; Obayashi et al., 2002).

\section{Extensive long-distance pollen dispersal}

Most pollination events in the three plots could not be assigned to any potential pollen donor within the plot (mean GFO rates ranging from 66 to $74 \%$ ). While genotyping errors may result in overestimated GFO; Gerber et al. (2000) in a study of 89 oak trees using six microsatellites markers with allelic richness similar to ours demonstrated that they overestimated outside plot pollination by only $5 \%$. Hence genotyping ambiguities cannot explain our high GFO values: relatively longdistance gene flow is frequent in Sapelli. There is not a very strong mating advantage to neighboring plants. Indeed, we observed long-distance pollination within 
plots, over distances of 1027, 944 and $2095 \mathrm{~m}$ in Ndama 2002, 2003 and Dimako, respectively.

While we do not have any direct evidence on how Sapelli is pollinated, such gene flow suggests, if we follow Obayashi et al. (2002), that Sapelli is pollinated by mobile insects such as Apis and Trigona bees. Bee pollination would also be in agreement with the observed lack of directionality in pollen transfer. This conclusion is supported by the more general observation that the Meliaceae are usually insect pollinated, mainly by bees and moths (Styles and Khosla, 1976).

Our results are similar to those obtained for other tropical tree species using microsatellite markers. The GFO rate was estimated to be $62 \%$ in Dicorynia guianensis (Fabaceae: Caesalpinioideae) on a 40 ha plot located in a continuous forest area with $n=157$ trees (Latouche-Hallé et al., 2004). It was estimated to be $36 \%$ in Swietenia humilis (Meliaceae) on a 68 ha plot located at the edge of a continuous forest and half-surrounded by plains with $(n=97)$ trees (White et al., 2002). Hence extensive pollen flow is frequent in tropical trees.

\section{Limited variance of within-plot male success}

In each treatment, about one-third of the potential within-plot pollen donors were identified as being effective (35.6, 38.3 and $36.4 \%$ in Ndama 2002, Ndama 2003 and Dimako, respectively). This is a high proportion when taking into account numbers of seeds analyzed and numbers of potential parents within the plots. Further, although MMS has generally been found to be high in most species, in this case, each recognized male parent sired on average only 1.47, 2.33 and 2.66 of the genotyped seeds in Nadama 2002, Ndama 2003 and Dimako, respectively. Increasing sample size would probably have substantially increased the number of effective parents. This suggests that many more than one-third of adult trees produce male flowers every year; hence, male flowering is probably rather regular. In this respect, male flowering differs from female flowering and fruit set. Indeed, analyzing two sets of large Sapelli trees $(\mathrm{DBH} \geqslant 50 \mathrm{~cm}, n \approx 50)$ in the same locations (Ndama and Dimako) in 1998 and 1999, C. Dubois observed that, in any given year, only one-third of all trees set seeds (unpublished data).

As expected from the numerous observed within-plot pollen donors, kinship within progeny families did not differ among treatments and values of both allelic $(A)$ and genetic $\left(H_{\mathrm{e}}\right)$ diversity in progenies did not differ from those observed in within-plot pollen donors and mother trees. We conclude from these results that despite the flowering-tree density reduction caused by logging, genetic diversity in these populations of Sapelli is not endangered. The extensive pollen flow has sustained the genetic variation. Further, we may assume that even in the low-density treatment, pollen was not limiting seed production. Indeed, limiting pollen would probably have resulted in increased kinship within progeny families as a result of pollination by a restricted pool of pollen donors.

\section{Proximity effects}

Despite the observed long-distance gene flow, proximity effects were also present. Closely nearby trees were more likely to have pollinated a mother tree. While median within-plot detected pollination distances were 260, 156 and $268 \mathrm{~m}$, in Ndama 2002, Ndama 2003 and Dimako, respectively, the median distance to potential pollen donors were 493, 481 and $1137 \mathrm{~m}$. Further GFO decreased or tended to decrease with distance from the edge of the plot, suggesting such proximity effects.

These values are within the range of average pollination distances commonly observed in studies of tropical trees (Hamrick and Murawski, 1990; White et al., 2002; Kenta et al., 2004). This pattern seems to be common to tree species in which individuals are widely dispersed, even in temperate forests (Gerber et al., 2003b). Nevertheless, as the GFO rate observed in each treatment showed that more than half of the known pollen donors were situated outside the plot (66-74\%), true average pollination distances in Sapelli are much larger.

The significant reduction of observed within-plot pollination distances between Ndama 2002 and Ndama 2003, and the lack of difference between Ndama 2002 and Dimako could be explained by a two-step process in which close neighbors are more favored at intermediate densities but when density becomes even lower there are no more close neighbors. This result needs to be confirmed. Nevertheless, pollination by within-plot neighbors never accounted for more than about onethird of pollination.

While there was a slight tendency for mother trees to be heterozygotes, we observed a low $(<4 \%)$ but consistent deficit in heterozygotes in all progenies. This deficit indicates minor but significant biparental inbreeding and correlated mating, which could be explained by the slight spatial structuring. Indeed limited seed dispersal (almost all seeds collected close to a mother tree effectively came from that tree) associated with some pollination by nearby trees may be sufficient to have generated such a structuring.

Lee (2000) reported similar results in a natural population of Shorea leprosula (Dipterocarpaceae), with maternal trees exhibiting a significant excess of heterozygotes $\left(F_{\text {is }}=-0.078\right)$ whereas progenies exhibited a deficit $\left(F_{\text {is }}=0.089\right)$. Such a pattern is frequently reported in studies of natural tree populations (Hufford and Hamrick, 2003). We suggest, like Lee (2000), that this pattern could be explained by selection against even slight inbreeding during the growth of seedlings to seedproducing size.

\section{Size effects}

In Ndama, we did not detect any effect of tree size on male reproductive success, but there was a striking one in Dimako. In Dimako, the size distribution of trees was biased toward small trees (Figure 2c). This resulted in a stronger contribution of small trees to pollination than in Ndama. However, the large trees (size class (100119) $\mathrm{cm}$ ) in DBH were overrepresented among the known within-plot pollen donors and each known within-plot pollen donor of that size contributed to the fertilization of more seeds. This suggests that (1) large trees are more efficient pollen donors than smaller ones, but (2) in Ndama, competition among large trees reduces their average success and (3) numbers of seeds sampled and number of small trees were not sufficient to detect whether small trees are less efficient pollen donors. Nevertheless the result depends on a single treatment, 
and within that treatment, there are not enough representatives of each size class to test for whether results could alternatively be explained by the spatial disposition of the trees.

\section{Conclusion}

We conclude that pollination of Sapelli is a mix of local and long-distance pollen flow, the latter being predominant, in both primary and logged forests. Long-distance pollen is sufficiently prevalent to have a strong homogenizing effect on the regional gene pool in the diffuse Sapelli populations, whatever the local densities of flowering individuals.

Inbreeding and correlated matings remain low even at low densities. This pattern probably results from a strong self-incompatibility mechanism and from the contribution of many different trees to pollination: even at low densities, pollen does not seem to be limiting. The early male flowering, beginning at $20 \mathrm{~cm} \mathrm{DBH}$, combined with later fruiting, beginning at $50 \mathrm{~cm} \mathrm{DBH}$, will have augmented the diversity of pollen donors. Consequently, even following heavy logging, a sufficient density of potential male parents seems to be spared to ensure a diverse genetic composition of progenies. Hence, in Sapelli, we may suggest that rules for sustainable tree extraction can be based solely on regeneration patterns without worrying about their genetic consequences. We may contrast our conclusion for Sapelli with Shorea curtisii (Obayashi et al., 2002). In that species, reduced densities after logging resulted in a dramatic increase in selfing. Hence, predicting the consequences of logging policies and regulations requires genetic studies on the species in question.

\section{Acknowledgements}

We are grateful to A Mbenda and the field workers for help in collecting material in the field, $\mathrm{H}$ Vignes, M-P Dubois and C Debain for help in the laboratory work, $S$ Gerber for helpful comments on the paternity analysis, $\mathrm{P}$ Jarne and D McKey for comments on the manuscript. This work was supported by funds from Cirad (Centre de Coopération Internationale en Recherche Agronomique pour le Développement).

\section{References}

Aubreville A (1959). La flore forestière de la Cote d'Ivoire Publication no. 15 du CTFT, Nogent sur Marne, France, Tome II, 341p.

Bawa KS (1990). Plant pollinator interaction in tropical rain forests. Annu Rev Ecol Syst 21: 399-422.

Bawa KS (1992). Mating system, genetic differentiation and speciation in tropical rain forest plants. Biotropica 24: 250-255.

Benjamini Y, Hochberg Y (1995). Controlling the false discovery rate - a practical and powerful approach to multiple testing. $J$ R Stat Soc Ser B 57: 289-300.

Chaix G, Chantal I, Poitel M, Razafiarivelo S, Verhaegen D, Maillard J-C (2002). Microsatellite primer amplification by multiplexing: a first application to Eucalyptus grandis. Plant Mol Biol Rep 20: 1-5.

Cunningham SA (2000). Effects of habitat fragmentation on the reproductive ecology of four plant species in mallee woodland. Cons Biol 14: 758-768.

Dawson IK, Waugh R, Simons AJ, Powell W (1997). Simple sequence repeats provide a direct estimate of pollen- mediated gene dispersal in the tropical tree Gliricidia sepium. Mol Ecol 6: 179-183.

Dayanandan S, Dole J, Bawa K, Kesseli R (1999). Population structure delineated with microsatellite markers in fragmented populations of a tropical tree Carapa guianensis (Meliaceae). Mol Ecol 8: 1585-1592.

Détienne P, Oyono F, Durrieu de Madron L, Demarquez B, Nasi R (1998). L'analyse des cernes : applications aux études de croissance de quelques essences en peuplements naturels de forêt dense africaine;. Projet FORAFRI 36p.

Doligez A, Joly HI (1997). Mating system of Carapa procera (Meliaceae) in the French Guiana tropical forest. Am J Bot 84: 461-470.

Durrieu de Madron L, Daumerie A (2004). Diamètre de fructification de quelques essences en forêt naturelle centrafricaine. Bois et Forêts des Tropiques 281: 87-95.

Dutech C, Seiter J, Petronelli P, Joly HI, Jarne P (2002). Evidence of low gene flow in a neotropical clustered tree species in two rainforest stands of French Guiana, Vouacapoua americana. Mol Ecol 11: 725-738.

El-Mousadik A, Petit RJ (1996). High level of genetic differentiation for allelic richness among populations of the argan tree (Agrania spinosa (L) Skeels) endemic to Morocco. Theor Appl Genet 92: 832-839.

Garcia F, Noyer L, Risterucci A-M, Chevallier M-H (2004). Genotyping of mature trees of Entandrophragma cylindricum with microsatellites. J Hered 95: 454-457.

Gerber S, Chabrier P, Kremer A (2003a). FaMoz: a software for parentage analysis using dominant codominant and uniparentally inherited markers. Mol Ecol Notes 3: 479-481.

Gerber S, Latouche-Halle C, Lourmas M, Morand-Prieur M-E, Oddou-Muratorio S, Schibler L et al (2003b). Mesure directe des flux de gènes en forêt. Les actes $d u$ BRG 4: 349-368.

Gerber S, Mariette S, Streiff R, Bodenes C, Kremer A (2000). Comparison of microsatellites and amplified fragment length polymorphism markers for parentage analysis. Mol Ecol 9: 1037-1048.

Ghazoul J, Liston KA, Boyle TJB (1998). Disturbance-induced density-dependent seed set in Shorea siamensis (Dipterocarpaceae) a tropical forest tree. J Ecology 86: 462-473.

Goudet J (1995). FSTAT (Version 12): a computer program to calculate F-statistics. J Hered 86: 485-486.

Hall JB, Swaine MD (1976). Classification and ecology of closedcanopy forest in Ghana. J Ecol 64: 913-951.

Hall P, Walker S, Bawa K (1996). Effect of forest fragmentation on genetic diversity and mating system in a tropical tree Pithecellobium elegans. Cons Biol 10: 757-768.

Hamrick JL, Murawski DA (1990). The breeding structure of tropical tree populations. Plant Species Biol 5: 157-165.

Hardy OJ, Vekemans X (2002). SPAGEDi: a versatile computer program to analyse spatial genetic structure at the individual or population levels. Mol Ecol Notes 2: 618-620.

Hawthorne WD (1995). Ecological profiles of Ghanaian forest trees. Tropical Forestry Papers, 29th edn. Oxford Forestry Institute: Oxford. vi+345pp.

Hufford KM, Hamrick JL (2003). Viability selection at three early life stages of the tropical tree, Platypodium elegans (Fabaceae, Papilionoideae). Evolution 57: 518-526.

Kaufman SR, Smouse PE, Alvarez-Buylla ER (1998). Pollen-mediated gene flow and differential male reproductive success in a tropical pioneer tree Cecropia obtusifolia Bertol (Moraceae): a paternity analysis. Heredity $\mathbf{8 1}$ 164-173.

Kenta T, Isagi Y, Nakagawa M, Yamashita M, Nakashizuka T (2004). Variation in pollen dispersal between years with different pollination conditions in a tropical emergent tree. Mol Ecol 13: 3575-3584.

Kitamura K, Yusof ARM, Ochiai O, Yoshimaru H (1994). Estimation of outcrossing rate on Dryobalanops aromatica Gaernt $\mathrm{F}$ in primary and secondary forests in Brunei Borneo Southeast Asia. Plant Species Biol 9: 37-41. 
Latouche-Halle C, Ramboer A, Bandou E, Caron H, Kremer A (2004). Long-distance pollen flow and tolerance to selfing in a neotropical tree species. Mol Ecol 13: 1055-1064.

Lee SL (2000). Mating system parameters of Dryobalanops aromatica Gaertn $\mathrm{f}$ (Dipterocarpaceae) in three different forest types and a seed orchard. Heredity 85: 338-345.

Lee SL, Wickneswari R, Mahani MC, Zakri AH (2000). Mating system parameters in a tropical tree species Shorea leprosula Miq (Dipterocarpaceae) from Malaysian lowland dipterocarp forest. Biotropica 32: 693-702.

Loiselle BA, Sork VL, Nason J, Graham C (1995). Spatial genetic structure of a tropical understory shrub, Psychotria officinalis (Rubiaceae). Am J Bot 82: 1420-1425.

Loveless MD (1992). Isozyme variation in tropical trees: patterns of genetic organization. New Forests 6: 67-94.

Marshall TC, Slate J, Kruuk LEB, Pemberton JM (1998). Statistical confidence for likelihood-based paternity inference in natural populations. Mol Ecol 7: 639-655.

Murawski DA, Hamrick JL (1991). The effect of the density of flowering individuals on the mating systems of nine tropical tree species. Heredity 67: 167-174.

Nagamitsu T, Ichikawa S, Ozawa M, Shimamura R, Kachi N, Tsumura Yet al (2001). Microsatellite analysis of the breeding system and seed dispersal in Shorea leprosula (Dipterocarpaceae). Int J Plant Sci 162: 155-159.

Nason JD, Hamrick JL (1997). Reproductive and genetic consequences of forest fragmentation: two case studies of neotropical canopy trees. J Hered 88: 264-276.
Obayashi K, Tsumura Y, Iharaujino T, Niiyama K, Tanouchi H, Suyama Y et al (2002). Genetic diversity and outcrossing rate between undisturbed and selectively logged forests of Shorea curtisii (Dipterocarpaceae) using microsatellite DNA analysis. Int J Plant Sci 163: 151-158.

Raymond M, Rousset F (1995). GENEPOP (version 12): population genetics software for exact tests and ecumenicism. J Hered 86: 248-249.

Ritland K (2002). Extensions of models for the estimation of mating systems using $\mathrm{n}$ independent loci. Heredity 88: 221-228.

Stacy EA, Hamrick JL, Nason JD, Hubbell SP, Foster RB, Condit R (1996). Pollen dispersal in low-density populations of three neotropical tree species. Am Nat 148: 275-298.

Styles BT (1972). The flower biology of the Meliaceae and its bearing on tree breeding. Silvae Genet 21: 175-182.

Styles BT, Khosla PK (1976). Cytology and reproductive biology of Meliaceae. In: Burley J, Styles BT (eds). Tropical Trees Variation, Breeding and Conservation. Linnean Society Symposium Series no. 2. Academic Press: London. pp 61-67.

Ward M, Dick CW, Gribel R, Lowe AJ (2005). To self, or not to self. A review of outcrossing and pollen-mediated gene flow in neotropical trees. Heredity 95: 246-254.

White GM, Boshier DH, Powell W (2002). Increased pollen flow counteracts fragmentation in a tropical dry forest: an example from Swietenia humilis Zuccarini. Proc Natl Acad Sci USA 99: 2038-2042. 